Estudios Atacameños No 16 - 1998

\title{
Peine: Saber andino, manejo de recursos y transformaciones
}

Marie Karolina NúÑ̃z S.*

\section{RESUMEN}

Los pueblos andinos, tienden a pensar el espacio y manejar el máximo de recursos disponibles, a través de una estrategia ecológica subjetiva, conducente a presentar respuestas que, en este caso, los habitantes del oasis de Peine reflejan en distintos ámbitos del ciclo de la vida cotidiana. A través de las nociones propias de su sabiduría, con adaptaciones científicas en torno a la organización y administración, consistente en el paisaje como recurso, se advierte en este oasis un proceso vertiginoso de cambios sustanciales. Se entiende así una situación étnica sustentada por entramados culturales en tensión, provocados no precisamente desde dentro, sino que, del impacto explícito de los agentes de cambio externos, hacia donde se extienden los entramados en un escenario frágil de fenómenos simultáneos de continuidad y cambios.

\section{ABSTRACT}

The Andean people trend to think the space and manage most of the available resources through a subjective ecological strategy, guiding to show answers that, in this case, the inhabitants of the oasis of Peine reflex in different situations of the cycle of the ordinary life. Through the own notions of their wisdom, with scientific adaptations around the organisation and administration, which consist in the landscape as a resource, a vertiginous

\footnotetext{
* Universidad Academia de Humanismo Cristiano; San-
} tiago de Chile.E-mail: fractal@netline.cl process of substantial changes is seen in this oasis. It is understood in this way a ethnic situation based on cultural framed works in tautness, caused not precisely from the inside, but from the explicit impact of the agents of the external changes, where the framed works are extended in a fragile scenery of simultaneous phenomena of continuity and change.

\section{Introducción}

Los oasis ubicados al sur del Salar de Atacama se han considerado como aislados y de menor acceso a los cambios por su distanciamiento de los centros de mayor transformación, como Calama y San Pedro de Atacama (Mostny 1954). Sin embargo, aunque el conocimiento andino o vernacular tiende a conservarse aquí, la introducción de cambios es cada vez más rápida, creándose escenarios dinámicos que requieren de nuevos análisis (Folla 1989; Hidalgo, B. 1992; Núñez, P. 1993).

La comprensión del espacio, en su vasta acepción, es lo que permite a mujeres y hombres andinos manejar un conjunto de conocimientos fundados en la praxis y habilidades para dominar un Saber, registrándose, además, bajo el soporte de la memoria y su transmisión oral. De esta manera, los conocimientos que se van adquiriendo y practicando en la vida cotidiana hacen que el contenido de la memoria se refuerce a partir de conceptos subjetivos (Vallée, 1970).

En la localidad de Peine, ubicada hacia el sector sur oriental del Salar de Atacama, se observan 
manejos de recursos-bienes, que los peineños organizan en el plano del ciclo productivo anual y ritual, es decir, una relación vital entre tiempo, espacio, recurso y pensamiento. Lo interesante es que esta comunidad ha presentado respuestas y soluciones en la administración de sus bienes. En este sentido, se expondrán algunos ejemplos representativos con el objeto de dar cuenta de algunos conocimientos locales respecto del manejo de los recursos, de sus respuestas para afrontar eventos de stress por crisis de escasez y, finalmente, señalar los escenarios en que se sitúan los saberes en relación a los agentes de cambio.

La información que contiene el presente artículo, está basada preferentemente en las notas de campo de la investigadora; en consecuencia, se jerarquiza la información de carácter etnográfica más que la bibliográfica.

\section{Conocimientos propios}

Sobre los conocimientos en uso, se identifica un máximo provecho de la zona en general y, de las tierras productivas con recursos, para el caso específico de la localidad de Peine. Este máximo provecho de la zona se refiere al conocimiento del espacio que rodea a Peine, fundamentalmente sobre el manejo de una geografía contrastada, como también de los medios que aporta la gradiente altitudinal, desde los lagos de altura hasta la playa del salar.

Se localiza, desde una perspectiva de oeste a este, un primer sector que corresponde al borde oriental del Salar de Atacama, allí se ubican vegas como las de Tilocalar y Tilopozo. Posteriormente, los oasis piemontanos, al cual pertenecen Peine y Tilomonte, caracterizados por sus arboledas (algarrobales y chañares) asociadas a una extensa productividad agraria y pecuaria. Siguiendo la gradiente, se localizan las quebradas intermedias con acceso al recurso-forraje, principalmente para las labores pastoriles. Y por último, el sector precordillerano y alta puna, con un aumento de vegetación natural, presencia de lagunas en altura y mayor humedad, permitiendo un hábitat adecuado para las tareas estacionales de pastoreo, especialmente las realizadas en las alturas de Pular. De este modo, la geografía de esta zona, se vincu- la a estos cuatro espacios que se conectan con diversos recursos y ambientes (Núñez, L. 1995).

En la propia localidad de Peine, las tierras productivas se ubican en el sector norte del pueblo, en una franja que se desplaza de este a oeste, indistintamente; por lo tanto se observa una organización del espacio natural de acuerdo a ciertas orientaciones. En este sector se ubican los terrenos, llamados por los peineños como chacras o melgas, asociados a una alta y extensiva productividad de maíz y alfalfa. Acerca del maíz, los más utilizados son el Cape y Morocho. El primero, es un maíz blando que se destina principalmente para el tostado y el Morocho, llamado amarillo, es más duro en relación al anterior y se emplea también para el tostado y para espesar la sopa actuando como sémola o harina, cuando se muele.

En sectores más reducidos, como la huerta, se siembran zapallo, lechuga, tomate, repollo, zanahoria, cebolla y las "verduritas" que son el cilantro y el perejil. Para el éxito de las cosechas, ha sido fundamental el uso del abono. La taxonomía del abono corresponde al de animal y de hoja (también llamado "de leña"). Los más usados y "mejores para la siembra" es el guano de cordero, burro y tierra de hoja; este último se encuentra en gran cantidad y calidad en la vega de Tilomonte. Ejemplos para la relación entre recursos y tipos de abonos, se citan los siguientes: para el maíz, se utilizan los de cordero, conejo y salitre. Para las "plantas chicas", como el cilantro, perejil y tomate principalmente, se prefiere utilizar el abono de hoja y, si éste no hubiere, se usaría el de cordero, pero no fresco, sino aquél que está en "el cerro" ya varios años. Para el zapallo, se usa el de gallina o conejo. También se encuentran otros abonos alternativos como el de chancho. Por lo tanto, en Peine habría una cultura del abono, como también se ha observado en Socaire y en Camar. Tradicionalmente se han usado los de tipo animal y los de hoja, experimentándolos en relación a las características de los recursos que se desean cultivar; sin duda alguna, han sido bastante exitosos. Respecto de los fertilizantes exógenos que han llegado a Peine, habla un testimonio respecto de esto y de la preparación de la tierra en relación a los abonos: "Con abono de animal, así se preparaba antes, pero ya más después, cuando empezó INDAP, empezó aquí a llegar otros abonos, pero eso era 
para el maíz, pero eso no le echábamos nosotros. Para el maíz, nosotros le echábamos el salitre. (...) El de corderito y el de burro; esos son los que más se usan para sembrar" (Núñez, 1998 Ms.).

Otros conocimientos tradicionales, se advierten en el manejo del riego, de bienes empleados en la vida diaria y de recursos usados como tecnología aplicada. El sistema de riego para las tierras cultivadas es de aproximadamente cada quince días y la administración de los turnos de agua le corresponde al juez de aguas, miembro que pertenece al Comité de Agricultores. Para que el sistema de riego sea exitoso, es necesario que todos los años los pobladores limpien sus estanques y canales para que sus venas distribuyan las aguas en todos los sectores de Peine. Otros recursos muy bien aprovechados son: el cuero, curtido de cuero de cordero, utilizado para la vida cotidiana y en artesanía; la piedra, para la construcción de casas, corrales, instrumentos para moler (kona) y todo aquello para la "fabricación en duro". La cantera, se encuentra en los altos de Peine. En madera, se encuentran las más características de la zona, como el chañar (Geoffroea decorticans), usada como tecnología aplicada en almadarada (armazón) para las casas y la de algarrobo (Prosopis chilensis), para la fabricación de telares, peines, lisos, entre otros.

En general, todos estos conocimientos vinculados con recursos se ligan al valor que estos tienen en relación a otros que se ubican en la gradiente altitudinal. Desde esta perspectiva, los intercambios de productos comestibles son necesarios para complementar la dieta alimenticia; no obstante que productos símiles se cultiven en varios sectores, la cantidad y calidad son las variantes que hacen emerger el trueque. De esta manera los pueblos de esta área, que habitualmente trocan entre sí sus productos, son Peine, Socaire y Toconao.

De acuerdo al relato de peineños, se dice que, aproximadamente hace cuarenta años atrás, el cambio que hacían con los pobladores de Toconao era de maíz y leña por frutas. La leña es la que llaman cachiyuyo y el cambio era una carga de leña por un cajón de fruta o carga por carga, ya sea por breva, alvarillo, damascos, manzanas y peras. Con Socaire, el cambio era de maíz por papa, por trigo y por habas; haciendo el trueque en la relación peso a peso. Otro antecedente de trueque con Socaire era el cambio que hacía un pastor peineño, hasta hace tres años atrás, de lana por alfalfa.

En los años que anteceden a la década del setenta, era común para los pobladores de Peine extraer la sal del Salar de Atacama y llevarla a Socaire en tres a cuatro cargas por vía animal, que correspondían alrededor de ocho bloques o barras de sal; por lo tanto y de este modo, el intercambio que hacían era sal por papas, por carne, por trigo y por habas. La equivalencia del cambio, de producto por producto, generalmente era peso a peso, pero a veces obedecía "según el tamaño" del bloque. La sal, aparte del consumo humano en comidas y particularmente en la preparación del charki de llamo, de cabro y de cuye, era y es excelente para el consumo animal, para "que no afloje la flacura" y para "que se componga la carne".

Actualmente, los peineños trocan con Socaire los siguientes productos: maíz por papa, por trigo y por habas; continúa la equivalencia peso a peso. Ya no existe el trueque de sal por productos socaireños. Con Toconao, permanece el trueque de maíz por fruta, tales como membrillos, manzanas, brevas, granadas, uvas, peras y también con naranjas, entre otros. Al parecer, el intercambio de leña por frutas ya habría dejado de ser una constante.

De los diversos conocimientos ya señalados, la mayoría continúa practicándose en los poblados que se distribuyen en el sector oriental del Salar de Atacama; sin embargo, de todos los saberes, el manejo del ganado sigue siendo uno de los más importantes para estos pueblos. La ganadería en Peine, mayoritariamente, es de crianza de corderos, clasificándose en varias razas, tales como "huasito", "tizana", "marino" y "mestizos". Los de tipo "San Pedro" no serían tan adecuados para la cordillera, ya que, de acuerdo al relato de los pastores de Peine, "son criados de otra forma, no andan y les pesca la puna; son animales pesados". Sin embargo, de igual modo se están criando corderos y ovejas en Tilomonte de tipo "San Pedro", aunque en menor grado en comparación con las otras razas. En este mismo contexto, el consumo de pastos y aguas, son de suma importancia para la reproducción del sistema. Los mejores pastos o 
"junquillos" para el engorde y óptimo desarrollo de los animales se les denomina localmente como "Iloca", "papolpasto" y "yerbasal". Sin embargo $\mathrm{y}$, por los problemas que ha traído el clima por sus permanentes heladas, el agua se ha puesto más fría afectando directamente a los animales. En consecuencia, se prefieren las aguas tibias y pastos de Tulan y Tilopozo. Por estos problemas, tales como el clima y otros que veremos más adelante, los pastores tienden a quedarse más tiempo en la estancia de Tilomonte, aprovechando en este caso los pastos de Purcelti, Kuman y Tilocalar.

En relación a los intercambios que hace el pastor de producto por producto, como lanas, cueros, maíces, choclos, entre otros, son realizados con sus vecinos y con conocidos o amigos de otros poblados, ubicados desde San Pedro de Atacama hasta Peine. Este tipo de intercambios se caracteriza por ser un trato distendido y seguro, que a su vez implica correspondencia y mantención de los lazos sociales.

Respecto de las ventas que hace el pastor, son básicamente de ovinos, lanas, cueros, maíces, choclos, entre otros, y se comercializan a nivel local y regional. Dentro de las compras de mayor importancia, están las de animales, precisamente de ovinos (machos reproductores y ovejas). Evidentemente que, ambas transacciones, pueden ser realizadas tanto con conocidos como con desconocidos o nuevos contactos.

Cuando el trato de compra y venta es realizado entre desconocidos, se sugiere sutilmente que la base del éxito del negocio es la desconfianza. De hecho se trata de comprar bien y vender mejor. Para este caso, se describirá un ejemplo sobre el negocio realizado entre el pastor de Peine y un poblador del ayllu de Sequitor, celebrado en este mismo ayllu. El pastor, es el comprador, y observa calmadamente en el corral a los animales que están en venta (edad, color, sexo y peso), señalando constantemente ser un entendido en esta materia; asimismo el vendedor indica los méritos de sus animales y, a pesar que le es de gran importancia vender, simula no estar muy interesado. Luego, se escoge el animal y se pesa. Entre tanto, el vendedor sigue convenciendo de las cualidades de sus animales y el pastor simula ciertas dudas, a pesar de estar muy conforme. Ya cerrado el trato, ambos conversan largamente sobre el buen negocio que han hecho y dejan pactados otros más (sobre animales, maíz, entre otros). Esta aparente y tal vez entidad de la desconfianza de ambas partes (estrategia), no sólo propicia el éxito del negocio y de otros futuros, sino que básicamente propicia el acceso a un nuevo lazo social. Respecto de esto último, se percibe que mientras más conocidos tenga una persona, ya sea en su localidad, región o macro región, más prestigio social detenta. ¿Hasta qué punto los intercambios (ya sean de cualquier tipo) o el acceso a cualquier recurso, traen consigo una lectura de prestigio, al acceder a un bien social y posteriormente económico? ¿Por qué el pastor no compró, esta vez, ganado en Socaire, siendo que allí tiene amistades y contactos seguros? Puede advertirse que, en el caso graficado entre el pastor de Peine y el poblador de Sequitor, circula entre líneas, del discurso de la compra-venta, la idea que cada una de las partes no tendría una necesidad explícita para comprar o vender (siendo que realmente es necesario); algo así como que cada parte tendría en su imaginario un paradigma de abundancia. ¿Sería esto un atisbo de prácticas antiguas? o, tal vez, ¿en el pasado, la estrategia era realmente obtener múltiples recursos (símiles o distintos), aunque su localidad o áreas circundantes cercanas, en cierta medida, se los brindaran? Si esto fuera probable y contrastable con el imaginario atacameño del siglo XXI, se podría comprender que el manejar, articular y experienciar el mundo de afuera a través de los viajes, por ende, manifestar reiteradamente ser conocido en su localidad y por sobre todo en tierras lejanas y, a la vez, mencionar sus lazos parentales, por ejemplo; sería una estrategia de acceso al prestigio social a partir de la interacción social que se suscita en otras tierras y que evidentemente trae consigo conveniencias o ventajas materiales: ¿prestigio a partir de una movilidad socioeconómica? La interdigitación étnica (Martínez, 1998) y las variantes del parentesco en zonas locales, cercanas y lejanas, podrían ser señales inequívocas del saber andino y del complejo entramado que trae consigo el manejo de múltiples recursos (Núñez, M. Ms.b).

\section{Los peineños frente a los eventos de stress, de escasez}

Para los eventos de crisis por escasez, en el cual se han visto expuestos los peineños, es posible 
exponer algunas respuestas que ellos han planteado. La más clásica y común en estos poblados es el almacenamiento y conservación del maíz, fruto del chañar y vainas de algarrobo. Para el maíz, cuando éste se cosecha aproximadamente a fines de marzo, "se pela", es decir, se saca "la chala" (las hojas) y se extiende en el granero para que se seque, guardándose posteriormente en sacos. En el caso del chañar y algarrobo, se espera que maduren, cayendo al suelo espontáneamente. Estos frutos se recolectan y, una vez secos, se guardan en sacos. Del chañar, se hacen budines, jaleas y otros subproductos; por otra parte, el algarrobo se chanca produciendo harina y se prepara, además, la aloja, que es una bebida fermentada, utilizada preferentemente en ceremonias.

Almacenar, es asegurar estos tres recursos significativos, para amortiguar la escasez que provoca la época de invierno. Estos productos se aprovechan para el consumo humano, de animales y para ser trocados en la misma comunidad, como también en localidades vecinas, habitualmente con Socaire.

Otra respuesta, en términos del saber tradicional, que han abordado excepcionalmente los peineños, trata sobre el problema del agua. En este caso, el agua salobre no permitía una buena cocción de los alimentos y se le atribuían inconveniencias en potabilidad. Para ello, la solución fue traer el agua desde Miscanti ${ }^{1}$ hacia el pueblo. Según el relato de los pobladores, la idea del "viaje del agua" surgió hace aproximadamente siete años atrás y la iniciativa se concretó cuando el pueblo presenta un proyecto donde adquieren fondos de varias instituciones estatales, mineras como la Sociedad Chilena del Litio y Escondida (este aporte tiene que ver con maquinaria y cañerías) y el dinero recaudado por los mismos pobladores, a partir del carnaval que se realiza en la época de verano. De esta manera, en abril de 1995, se hace el trazado de la ruta al alero de un prestigioso poblador.

La base del cerro Miscanti, está aproximadamente a unos $4.200 \mathrm{~m} . \mathrm{snm}$.
La traída del agua de Miscanti hacia Peine, específicamente desde una bocatoma que hicieron a unos dos kilómetros hacia el este de la laguna del mismo nombre, significó una reiteración en esta época de un conocimiento hidráulico que caracterizó a los pueblos primigenios. Se trató de un largo trabajo ejecutado a pala y rastrillo por los mismos pobladores de la comunidad. Esta labor trajo consigo paralelamente la construcción de un camino aledaño para el transporte e instalación de las cañerías de agua. Este nuevo camino parte desde un desvío de la ruta del camino internacional, con dirección al noroeste, pasando por quebrada Corquepe hasta llegar a los altos de Peine y al poblado en sí. Esto es, un ejemplo significativo del esfuerzo de trabajo comunal, que finaliza en julio de 1996. Después de traer el agua, vía cañerías hasta Peine, comienza la construcción del estanque de almacenamiento en 1997, ubicado en los altos del poblado. Ya, en estos momentos, la mayoría de la gente tiene en sus casas el agua de Miscanti.

Por otra parte, existen experimentaciones que se han realizado en Peine y alrededores, que funcionan como ejemplos claves para comprender y demostrar que aún los intentos de "domesticación del paisaje" son posibles. Sobre este tema, se mencionarán dos ejemplos. En el ámbito de la agricultura, en especial de frutales, esta localidad no ha sido caracterizada por sus logros en este rubro. Sin embargo, la siembra del membrillo, desde hace algún tiempo y por lo salobre del agua de vertiente, ha tenido buenos resultados.

En segundo lugar, se debe señalar el notable y exitoso esfuerzo de siembra y buen término de cosecha en Tilopozo. Esta experimentación, con óptimos resultados empíricos, fue lograda por un pastor de Peine (M. Chaile, comunicación personal), ya que alguna vez planeó manejar e integrar este sector más bien como centro operativo (al igual que Tilomonte), es decir, como parte del patrón de asentamiento disperso, que caracteriza a las actividades pastoriles. Los productos que se cosecharon en esa oportunidad fueron, cebolla, zapallo, verduritas, entre otros, similares a los que se obtienen en Peine; este intento prueba que aún hay agropastores que aspiran domesticar nuevos paisajes anexos. Lo interesante, para este caso, es que Tilopozo corresponde a la cota que fluctúa 
entre los 2.300 a $2.380 \mathrm{~m}$. snm, ubicándose en el borde oriental del Salar de Atacama, con altas oscilaciones térmicas, bajos niveles de precipitación, falta de arboledas típicas como el algarrobo y chañar, afloramiento de aguas salobres y costras y forraje natural con vertientes, no utilizados. Es conocida esta tierra como inhóspita para los procesos productivos; haciendo más meritorio el intento de valorarla (Núñez, L. 1995).

\section{Saberes y agentes de cambio}

Existe una serie de saberes propios que con el transcurso del tiempo y sobre todo por agentes externos de cambio, que han intervenido no sólo en esta comunidad, han ido desapareciendo en su práctica, replegándose al plano del recuerdo. Saberes que ya se han dejado de practicar, se pueden citar los siguientes ejemplos.

Las salidas realizadas por los peineños al Salar de Atacama, en búsqueda y colección de huevos de parina (phoenicoparrus sp.), formaban parte de los trabajos comunales, organizados por la autoridad local, ya que el beneficio de esta excursión era para todos los pobladores, particularmente por el valor nutritivo de este recurso (Mostny 1954). Años atrás, los pobladores partían hacia el salar en el mes de diciembre, época de nidificación de las parinas; a su vez, era de suma importancia recolectar sus plumas, en especial las rojas, las cuales eran usadas en ceremonias como el Talatur. Por efectos legales encabezados por CONAF, estas áreas cayeron bajo protección y en consecuencia de acceso controlado. Según el relato de los pobladores, la última vez que se agruparon para ir al salar en búsqueda de este recurso, fue en la década del setenta.

En el mismo salar, también una vez al año, en época de invierno se colectaba la sal. Los pobladores la sacaban del manto, es decir, que extraían la costra que es llamada "sal de espuma", "blanca" o amarga (sal no consumible). Debajo de la costra, se encontraba la "sal cristalina", que "es una granuladita, así como maíz"; ésta corresponde a la sal comestible. Habla el testimonio:

"Durante el tiempo que yo me he dado cuenta, es que la gente de aquí consumía sal del salar, entonces no se compraba la sal. Entonces se iba de acá a sacar sal del salar porque había una veta, como decían ellos; los viejitos ante una veta de sal la cortaban en barras de aproximadamente veinte kilos, más o menos. (...) Había un sendero ahí, en esos tiempos, un caminito, entonces los animales se iban por esa parte. Había una parte bien jodía, había un río, así que ahí había que pasar, justo los burros tenían que pasar por ahí, a la hora que se desvían, se hundian; era como un río y corría el agua. (...) Para ir a buscar la sal, había que ir en los tiempos de invierno, en tiempos en que ya no está la agricultura. Por ejemplo, si usted o nosotros íbamos a sacar sal por ahí en noviembre, decían los viejitos que venía la helada, que se helaban las chacras” (Núñez, M. 1998 Ms.).

La sal se canteaba con hacha, formando tres bloques que se cargaban a la mula; la distribución era de dos al costado de la mula y un tercero en el lomo, que se llamaba soborno. Para buscar la sal, se organizaban en pequeños grupos, entre familiares y/o vecinos. Normalmente, se demoraban medio día en el trayecto y oficio de la extracción de este mineral y "regresábamos a Peine con el cargamento de sal, para moler la sal, para hacer el charqui y para otras cosas".

A parte del consumo local de sal y cuando las fronteras eran blandas, un testimonio señala que:

“Durante el trayecto llevaban sal de acá
(Peine), porque venían de allá, de la Ar-
gentina, traían corderos, traían mulas, las
vendían y llegaban hasta San Pedro de Ata-
cama. (...) Los argentinos igual llevaban
sal, porque se demoraban casi quince a
veinte días en llegar al destino. Así de le-
jos, días caminaban, caminaban anima-
les...” (Núñez M. 1998 Ms.).

A comienzos de la década del setenta, la ruta de la sal se dejó de practicar, además hay que considerar que a partir de esta misma década los peineños comienzan a instalar el comercio en este poblado, aproximadamente en el año 1974. De este modo, la sal comprada en el comercio hace abaratar los costos. Sin embargo, aún se pueden hallar en rincones de corrales de Peine, los viejos bloques de sal para el consumo animal, provenientes del salar. 
Conocimientos que se están perdiendo con el tiempo, con la llegada de la medicina moderna y postas rurales, es el saber y manejo del uso de las plantas medicinales. Los abuelos son los que continúan con la vieja tradición de curarse vía yerbas o plantas. De una recolección de éstas, realizada en los alrededores de Peine, los abuelos reconocieron la mayoría de sus nombres y usos, además de los lugares donde se ubicarían, no así los jóvenes que tuvieron problemas en el momento de la clasificación. Algunos nombres y usos fueron los siguientes, de acuerdo a la ubicación en la gradiente altitudinal. Flora en el piso prepuneño o desértico: Kumi (Kume, Opuntia camachoi), excelente para saciar la sed. Tikara (Ambrosia artemisioides), procede contra el mal de orines; se prepara en infusión. Basal (Cistanthe celosioides). Kamin (Cistanthe salsoloides). Papolpasto (Papur pasto, Crytantha linearis). Flora en el piso puneño o tolar: Añawa (Adesmia spinosissima); su uso es para la prevención de infecciones y óptima para el lavado de pies. Chacha (Parastrephia quadrangularis), para sahumerio en los convidos de la limpia de canales y floreo de animales; denominada por lo tanto, como planta ritual. Kore (Acantholippia punensis), su uso es para el dolor de estómago y se prepara en infusión con té. Pingo pingo (Ephedra breana), actúa contra los problemas hepáticos, mal de orines y males en general; se prepara en infusión con mate o té. Konti (Lupinus oreophilus). Perlina (Perlilla, Junellia seriphioides). Quebrolla (Chuquiraga atacamensis). Flora en el piso altoandino o pajonal: Kopa kopa (Artemisia copa), excelente para el dolor de estómago; se prepara en infusión. Chuquican (Chuchikan, Mulinum crassifolium), actúa contra la tos, para los síntomas de puna y se bebe en infusión con mate. Y otros como Canchalagua, para la descompostura de sangre, comezón; se prepara en mate. Hueilavin, actúa contra el resfrío y previene los enfriamientos; se prepara en infusión con té. Flor de puna, Marancel y Quibuchi. ${ }^{2}$

La nomenclatura científica de la flora en correspondencia a los pisos ecológicos, se extrajo de la Guía de etnobotánica atacameña, distribuida en el Taller Internacional "Ciencia indígena en los Andes de Sudamérica"; preparada por la Dra. Carolina Villagrán.
En 1954, se informa para Peine las siguientes plantas medicinales y usos: Bailahuén, que actúa contra el dolor de riñones, preparándose en infusión; contra el aire (dolores provocados por corrientes de aire) y resfríos. Bailahuén, podría ser el concepto que, por el curso del tiempo, se ha transformado a Hueilavin. Copa Copa, actuaría contra el aire y dolores de estómago. Chuquicán, contra la tos, resfrío y romadizo. Maransel, contra los males del pulmón. Pingo pingo, contra la gonorrea, mal de orines; preparándose en cocción. Además, actúa contra la tos, en infusión (Mostny et al. 1954).

Otra práctica, que se podría denominar en transición, en vías de disolución, se refiere a las propias labores pastoralistas, asociadas directamente a la movilidad trashumántica en la zona. Es el caso de los dos últimos pastores de Peine, cuyo promedio de edad fluctúa entre los setenta años, sin reproducción del sistema vía herencia económica-cultural, por no tener descendencia. ¿Por qué pensar que el pastoralismo está siendo partícipe de un proceso de disolución? Desde 1932 a 1937, es decir, desde los diez a quince años de edad, el pastor de Peine comienza sus primeros aprendizajes sobre la crianza de animales (para ese tiempo, de llamas, corderos y ovejas). Hacia 1940, es decir, a la edad de dieciocho años, dice que encontró una estabilidad respecto de la crianza. Ya en 1958 declara "ser pastor" y haber contraído a su compañera en convivencia y empezar una vida juntos como pastores. Ya en la década del sesenta al setenta, era un ir y venir de Argentina, para surtirse, matutear (contrabando) y visitar. Al parecer, "el viaje", esa experiencia de movilidad, tanto por arriería o por intereses personales, constituye no sólo para el pastor hitos importantes, sino para la mayoría de los hombres del sur del Salar. En este contexto, se percibe que la arriería no ha sido una actividad opuesta al pastoreo, ya que según los pobladores, estos viajes implicaban ausencias de días, un mes y a veces varios meses, pero "a la vuelta" se continuaba normalmente con las actividades locales. Entre 1965 y 1970 dice tener la máxima cantidad de ganado, aproximadamente unas trescientas a cuatrocientas cabezas; aquí se encuentra la mayor agrupación del ganado para pastoreo. A fines de la década anterior, observa que comenzó a notar la sequía. Desde la década 
del setenta hasta 1991, los pastores de Peine han continuado con sus actividades, pero disminuyendo la masa ganadera. Desde 1992 hasta 1999 ya no se movilizan con sus animales hacia las cotas altas, específicamente a Pular (pastoreo estacional), ya que el sistema de trabajo que emprenden los enclaves mineros atrae desde aquí a sus trabajadores, marginando al pastor de parte de sus actividades productivas. En 1992, en efecto, es enrolado a un megaproyecto minero, introducido esta vez al mismo Salar. Desde esta fecha en adelante, el pastor vive tensionado entre el pastoreo estacional y su permanencia en la nueva actividad minera. No obstante, continúa en la minería por necesidad del salario. El turno de trabajo que le corresponde al pastor (nochero), es de diez días trabajados por tres de descanso. Esto impide la frecuencia de sus viajes (ya sea por pastoreo, intercambios o comerciales) y obstaculiza las actividades productivas de siembra y cosecha y, en general, todas las actividades de la vida cotidiana. Esto tiene una implicancia directa para las causas de fenómenos fuertemente contradictorios, ya que el modo de operar de la minería ha insertado otros parámetros de tiempo, que se podría llamar tiempo productivo, antagónico en relación con las actividades propias del ciclo anual. En 1995, los pastores tienen cien cabezas de ganado, agrupados en la vega de Tilomonte, desarrollando sólo una movilidad local. Además, para esta misma fecha hasta la actualidad, ha manifestado que hay personas foráneas interesadas en comprar sus terrenos en la vega ya mencionada, con la finalidad de ser usados, según la opinión del pastor, para turismo, reflejándose cambios operados desde San Pedro de Atacama (Núñez, M. 2000 Ms.).

Ésta es una realidad que esboza un escenario bastante complejo, ya que se enfrenta el saber y práctica local de una actividad específica con los agentes de cambio, que traen a su vez una serie de dispositivos de arranque que, al actuar (como lo hace la minera), indefectiblemente producen nuevos movimientos y nuevas respuestas. La llegada de la minería a fines de la década del sesenta como proyecto, tomó énfasis estructuralmente en los ochenta y en la actualidad, asociada a una pervivencia mínima de treinta años más en la zona. Esta es una de las causas que ha suscitado, como respuesta de los peineños, la desarticulación progresiva de la actividad pastoril; entregando a estos pobladores otras visiones para el remodelamiento cultural e innovaciones de la vida cotidiana en general.

La llegada de la escuela a Peine y en particular en la década del treinta, de profesores de la filosofía chilenizadora, clásica para la época, es otro ejemplo tácito de un agente de cambio externo. En este sentido, lo notable de esta generación de profesores eran sus técnicas aplicadas a los contenidos que entregaban sus cátedras, como la extirpación de Saberes y la de "civilizar a los indígenas" (sic). Las prácticas de fiestas y rituales, realizadas por sus alumnos, eran sancionadas posteriormente dentro del aula, con agresiones de carácter sicológicas y físicas. Así se "educó" a una generación completa por más de treinta años. Habla un testimonio:

"Si nosotros perdimos tanta riqueza sobre de tradiciones y todo eso, fue por el asunto del profesor que había acá. Un profesor que vino y no le gustaba nada las tradiciones y ninguna cosa. Nos castigaba a nosotros si estábamos en una fiesta o en una minga por ahí, en la limpia de canales, en todo nos castigaba el profesor. Así que nosotros, por el temor que nos castigue el profesor, nosotros nos manteníamos en casa, así que hacían los viejitos solos no más. Y entonces, nosotros fondeados aquí; entonces, ¿qué íbamos a recuperar?, nada, ¿qué íbamos a aprender?, nada tampoco. Ese ha sido el error más grande que tuvo el profesor éste, lamentablemente. (...) Vino muy joven acá, de diez y siete años ese profesor. Aquí se casó, tuvo terrenos, todo eso. Entonces, él fue modernizando el nombre de los terrenos, inclusive los que tenía él los cambió de nombre, les puso otros nombres modernos, nada que ver con los nombres de los que estaban antiguamente y cosas..., que los nombres de los terrenos, de los campos, de todo eso, son cosas de que tenemos que tenerlo acá, porque son netamente de la zona, netamente atacame$\tilde{n} a$, netamente de los pueblos. Entonces, ese profesor se dedicó a eso." 
Otro poblador testifica:

"Nos castigaba al otro día, en la escuela. Cuando ya nos veía que estábamos intruseando, andando por ahí. Y él salía en las noches a buscarnos, salía a buscarnos, a mirarnos; y a los días estábamos listos en la lista. Al frente no más y ahí nos castigaba. (...) Nos mandaba a buscar a cada uno dos piedras grandes y piedrecitas chicas. (...) Y las rodillas ahí aguantando arriba de las piedrecitas. Pero las piedras incrustadas en la carne, ahí en la rodilla, incrustada. Cuando se le iba bajando (los brazos del niño que sostenía las piedras con las manos) le mandaba el palo, tenía que enderezar uno y volvía el otro a caerse, igual, y volvía a pegar, y al cansancio uno ya no daba más. Claro, era malo el profesor de esos años. De ahí se fue perdiendo (las tradiciones), esa fue la realidad de las cosas de aquí. El maestro, nos prohibía lo que era natural de aquí de Peine, si no hubiéramos tenido todas las costumbres al día” (Núñez, M. 1998 Ms.).

Los alumnos de ayer, los adultos de hoy, tocan muy sentidamente este tema y le responsabilizan algunos olvidos, especialmente sobre tradiciones, otrora cotidianas. Es indudable que no fue bien visto para este profesor el valor ritual asociado a las actividades tradicionales, llámense floreo, convido, talatur, carnaval (con representación del pujiai), etc. Por lo tanto, no es extraño observar que los hijos de esta generación educada por estos profesores sean incitados a logros personales, a la educación formal completa (hasta la universidad si es posible), para que sean "alguien en la vida", "independientes" y de "progreso", es decir, que de alguna manera son dispuestos al discurso na- cional. Sin embargo, y a pesar de ver algunas formas de expresiones que aparentemente no encajan en una sociedad de adscripción étnica, hay un fondo común que es la memoria colectiva, que asienta y refuerza identidad; que a pesar de los olvidos, también recuerda..., crea y recrea, readapta o transforma; en fin, éstas son algunas respuestas que ha encontrado Peine para ser peineños ahora.

En síntesis, este artículo ha intentado, a través de varios casos, dar a conocer una realidad transicional que funciona no solamente para el caso de Peine, sino que también para los poblados de los alrededores y en general para todos aquellos que poseen estas características. Es decir, que, dentro del contexto de continuidad, se está en presencia de una sociedad que articula conocimientos propios, con una vasta comprensión de múltiples saberes (pluricultura), con manifestaciones empíricas andinas; sin embargo, y en el escenario de los cambios (Gundermann 1998), sus prácticas se han visto enfrentadas a transformaciones y desarticulaciones notables, producto de agentes externos. Ya se han mencionado algunos impactos ocasionados para Peine, como también las respuestas que en general se han presentado. Por lo mismo, las culturas al ser dinámicas y reconstructivas no desaparecen, ni se aniquilan, ya que siempre existe una memoria, un rastro, una ruta, un monumento, movimientos y voces que la refuercen, en un permanente estado de haciéndose entre lo interior y exterior.

Agradecimientos La autora agradece a la investigadora Victoria Castro por la invitación al presente evento y sobre todo por exponer estas materias aún en proceso de elaboración. Debido a que hace años que comparto con los vecinos de Peine estas preocupaciones, a ellos mis principales agradecimientos. 


\section{BIBLIOGRAFIA}

FOLLA, J. CH. 1989

Anthropologie économique d'une communauté paysanne du désert d'Atacama: Socaire. Université de Montréal, Montreal.

GUNDERMANN, H. Etnicidad, identidad étnica y ciudada1998 nía en los países andinos y el norte de Chile. Los términos de la discusión y algunas hipótesis de investigación. Estudios Atacameños 13 Pp. 9-26, San Pedro de Atacama.

HIDALGO, B. Organización social, tradición y 1992 aculturación en Socaire, una aldea atacameña. Memoria para optar al título de antropólogo social, Facultad de Ciencias Sociales, Universidad de Chile, Santiago.

VALLEE, L. La ecología subjetiva como elemento 1970 esencial de la verticalidad. XXXIX Congreso internacional de Americanistas. Actas y Memorias, Lima.

MARTINEZ, J. L. Pueblos del Chañar y el Algarrobo. 1998 Los Atacamas en el siglo XVII. Dirección de Bibliotecas, Archivos y Museos, Santiago.

MOSTNY, G., F. JELDES y R. GONZALEZ. Peine, un pue1954 blo atacameño. Instituto de Geografía, Universidad de Chile, Santiago.
NUÑEZ, L.

1995

1998 Ms.

$2000 \mathrm{Ms}$. Antropología y Título de Antropóloga Social, Universidad Academia de Humanismo Cristiano.

NUÑEZ, P. 1993

Posibilidades agrícolas y población del Incario en el área atacameña. Norte de Chile. Actas del XII Congreso Nacional de Arqueología Chilena. Sociedad Chilena de Arqueología, Dirección de Bibliotecas, Archivos y Museos, Museo Regional de La Araucanía; Tomo I, Pp. 259-267; Santiago. 